\title{
CRESCIMENTO SOB RESTRIÇÃO EXTERNA EM PAÍSES DE RENDA MÉDIA: UMA ANÁLISE EMPÍRICA DA LEI DE THIRLWALL MULTISETORIAL (2000-2013) ${ }^{\circ}$
}

\author{
GROWTH UNDER EXTERNAL CONSTRAINT IN MIDDLE-INCOME \\ COUNTRIES: AN EMPIRICAL ANALYSIS OF MULTI-SECTORAL \\ THIRLWALL'S LAW (2000-2013) \\ Henrique Rogê Batista* \\ Henrique Dantas Neder**
}

enviado: 02 octubre 2018 - aceptado: 08 abril 2019

\begin{abstract}
Resumo
O artigo visa testar a validade do modelo de crescimento sob restrição do balanço de pagamentos segundo a Lei de Thirlwall Multisetorial (2007) para um grupo de 69 países de renda média entre 2000 e 2013. Os resultados apontam para a validade da lei testada, que apresentou relevante poder preditivo da taxa de crescimento efetiva, e constatam que o crescimento de tais economias sofreu restrição pelo balanço de pagamentos. Dada a não significância estatística das variáveis que compõem o modelo, o mesmo não pode ser afirmado para uma amostra desagregada de 15 países. Os resultados ainda destacam a importância da composição setorial no comércio internacional e a heterogeneidade da amostra.
\end{abstract}

Código JEL: F14, F40, O41.

Palavras-chave: crescimento econômico, restrição externa, Lei de Thirlwall

Batista, H. R. \& Neder, H. D. (2020). Crescimento sob restrição externa em países de renda média: uma análise empírica da Lei de Thirlwall multisetorial (2000-2013). Estudios económicos, 37 (74), 127-160.

* Professor Adjunto da Universidade Federal do Mato Grosso (UFMT). Endereço eletrônico: henriqueroge@hotmail.com

** Universidade Federal do Maranhão. Endereço eletrônico: hdneder@gmail.com 


\begin{abstract}
The article aims to test the validity of the growth model under a balance of payments constraint according to the Multi-sectoral Thirlwall's Law (2007) for a group of 69 middle-income countries between 2000 and 2013. The result shows the validity of the law, which denotes the relevant predictive power of the effective growth rate, and presents that the growth of these economies was restricted by the balance of payments. Given the non-statistical significance of the variables composing the model, the same cannot be stated for a disaggregated sample of 15 countries. The results also highlight the importance of sectorial composition in international trade and the heterogeneity of the sample
\end{abstract}

JEL Code: F14, F40, O41.

Keywords: economic growth, external constraint, Law Thirlwall. 


\section{INTRODUÇÃO}

A literatura Pós-Keynesiana dos modelos de crescimento com restrição intertemporal do balanço de pagamentos faz parte de uma das classes mais amplas de modelos de inspiração keynesiana liderados pela demanda, nas quais as condições de demanda inferem sobre a limitação de divisas disponíveis, e, consequentemente, assume papel ímpar em explicar o crescimento das economias, com destaque para os países em desenvolvimento (Setterfield, 2006; McCombie \& Thirlwall, 1994).

A ampla aceitação e aplicação empírica da Lei de Thirlwall (LT) deu origem, na literatura econômica, a adaptações na lei original, que buscaram incorporar as críticas do modelo, bem como adaptá-las à realidade econômica dos países, sobretudo à daqueles subdesenvolvidos (Thirlwall, 2011). Dentre tais adaptações, a Lei de Thirlwall Multisetorial (LTM), modelo de Araújo e Lima (2007), leva em conta a estrutura setorial, de acordo com os valores das médias ponderadas das elasticidades-renda e preço da demanda por exportações e importações em setores da economia. Nesta versão, a LTM consiste na derivação da taxa de crescimento compatível com o equilíbrio do balanço de pagamentos, tendo em vista a teoria pasinettiana do papel da mudança estrutural da demanda, no contexto Multisetorial, sobre o crescimento econômico.

Entretanto, a literatura econômica dos modelos de crescimento econômico Pós-Keynesianos que captam a abordagem setorial ainda é restrita, considerando-se a sua relevância e o conceito de mudança estrutural para o crescimento (Kaldor, 1968 \& Pasinetti, 1981). A amostra selecionada de 69 países de renda média se justifica pelo lento ritmo da elevação da renda observada entre eles, salvo exceções, bem como da dificuldade de tais países em ocuparem estratos superiores de renda per capita (Gill \& Kharas, 2007).

Neste contexto, o objetivo deste trabalho é testar a validade da Lei de Thirlwall Multisetorial (2007) para o grupo de 69 países de renda média, usando dados anuais de 2000 a 2013 e, consequentemente, constatar se o crescimento médio desse conjunto de países foi restrito pelo balanço de pagamentos. Para isto, são estimadas as elasticidades-preço e renda das exportações e importações (variáveis explicativas) do valor exportado e importado (variáveis dependentes). Estas elasticidades são desagregadas por intensidade tecnológica conforme Lall (2000), e estimadas segundo a metodologia de dados em painel dinâmico via Método dos Momentos Generalizados (GMM-System). Para o teste da validade da lei, serão utilizadas técnicas comuns nesta literatura, que consistem em comparar as taxas 
de crescimento efetivo com a estimada, além da realização do teste de regressão entre tais taxas. Por fim, a fim de elucidar a heterogeneidade da amostra, a segunda parte da análise dos resultados esboça brevemente a composição setorial do balanço comercial de uma amostra de quinze países de renda média e estima, de forma desagregada, suas respectivas elasticidades renda (o critério de seleção desta amostra menor leva em conta o volume exportado e importado em 2013). Com isto, busca-se corroborar a relevância das commodities e produtos de menor intensidade tecnológica na pauta exportadora em detrimento da importação de produtos de maior intensidade tecnológica, além de estabelecer paralelos entre as elasticidades individuais com a do grupo de países.

O recorte temporal se justifica diante da necessidade de se constatar se mesmo perante o dinamismo do comércio internacional, que valorizou as commodities e cuja participação na pauta exportadora é relevante entre os países de renda média, é persistente a restrição externa ao crescimento. Embora componha um grupo de países heterogêneos, a agregação para os testes empíricos é justificada, salvo exceções, pela composição setorial do balanço comercial, pela faixa da renda per capita média e pelos entraves ao crescimento dado à limitação das divisas, fenômeno também comum a este grupo de países.

A contribuição deste artigo está em elucidar a relação entre a manutenção do equilíbrio do balanço de pagamentos e o desempenho do produto econômico do conjunto dos países de renda média. Isto, por sua vez, perpassa explanar a relevância dos termos de intercâmbio e da composição do balanço comercial.

O trabalho está dividido em três seções, além desta introdução e das considerações finais. A seção um aborda a revisão bibliográfica e o modelo da Lei de Thirlwall Multisetorial (2007); a seção dois descreve a metodologia e as variáveis utilizadas e, por fim; a seção três discute os principais resultados obtidos.

\section{REVISÃO BIBLIOGRÁFICA}

A literatura Pós-Keynesiana do modelo de Restrição no Balanço de Pagamentos de Thirlwall (1979), Lei de Thirlwall (LT), parte do contexto do crescimento determinado pelas condições de demanda, no qual as exportações assumem uma posição fundamental para o crescimento em economias capitalistas abertas. Neste contexto, o equilíbrio na balança de pagamento no longo é a restrição ao crescimento e, consequentemente, também permite explicar as divergentes taxas da elevação de renda entre as economias. 
As elasticidades renda da demanda por exportações e importações da LT correspondem aos valores agregados das médias ponderadas das elasticidades setoriais da economia. Dos vários modelos derivados a partir da LT, o modelo de Araújo e Lima (2007), Lei de Thirlwall Multisetorial (LTM), permite considerar estas elasticidades desagregadas por setores da economia.

A LTM é estruturada a partir dos modelos de Pasinetti (1981, 1993), que destacam o papel da mudança estrutural da demanda no contexto Multisetorial, e da LT do crescimento sob restrição externa do balanço de pagamentos. A 'structural economic dynamics' de Pasinetti $(1981,1993)$ tem que as mudanças estruturais influenciam a taxa de crescimento dos países. Partindo da teoria do crescimento conduzido pela demanda, a divergência entre as taxas de crescimento dos distintos setores da economia faz da estrutura produtiva um componente ímpar para explicar o crescimento agregado da economia. Além disto, o autor destaca que as elasticidades-renda setoriais não só são divergentes, como também apresentam comportamentos distintos no tempo conforme a renda per capita. As conclusões derivadas da LTM podem ser interpretadas considerando a taxa de crescimento da renda per capita de um país, estando relacionada às elasticidades-renda setoriais das exportações e importações. Essas elasticidades são ponderadas pelos coeficientes que medem a participação de cada setor no total das importações e exportações, respectivamente. A principal implicação do modelo Multisetorial é que alterações na composição da demanda, que não se refletem em mudanças nas elasticidades, mas na participação de cada setor na exportação ou importação agregada, também importam para o crescimento econômico. Ou seja, o crescimento com equilíbrio no balanço de pagamentos depende das elasticidades-renda do comércio exterior e da composição setorial da economia (Soares e Teixeira, 2012).

Thirlwall (2011) afirma, com base na LTM, que políticas de promoção de exportações e de substituição de importações permitem que o país cresça a taxas mais aceleradas a partir do momento em que, mesmo mantidos constantes as elasticidades setoriais e o crescimento mundial, transfira recursos aos setores com maiores elasticidades-renda da demanda por exportações, em detrimento dos setores com elevada elasticidade-renda das importações.

A formalização da $\mathrm{LTM}^{1}$ pode-se dar considerando a existência de dois países: o país avançado A e o país em desenvolvimento U; em que ambos produzem

1 A formulação do modelo é a mesma apresentada por Araújo e Lima (2007) no seu artigo publicado na Cambridge Journal of Economics intitulado: 'A structural economic dynamics approach to balance-of-payments constrained growth'. 
$n-1$ bens de consumo. Os fluxos monetários e de mercadorias do país U admitem três pressupostos: a condição de pleno emprego, a condição de pleno dispêndio da renda e o equilíbrio do balanço de pagamentos.

Sejam os coeficientes de demanda per capita doméstica e externa representados por $a_{i n}$ e $a_{i \hat{n}}$, respectivamente, e o coeficiente de produção de bens de consumo, que representa a quantidade de trabalho empregada em cada setor $i$, denotada por $a_{\hat{n} i}$; onde $i=1,2, \ldots, n-1$. Além disto, considere-se que o setor de famílias no país A é representado pelo subscrito $\hat{n}$ e $\zeta$ é o coeficiente de proporcionalidade entre a população de ambos os países. Feitas tais considerações, a condição de pleno emprego pode ser representada como:

$$
\sum_{i=1}^{n-1}\left(a_{i n}+\zeta a_{i \hat{n}}\right) a_{n i}=1
$$

Da mesma forma, se $a_{i \hat{n}}$ é o coeficiente da demanda per capita por importações do bem de consumo $i$ produzido pelo país A, a condição de pleno dispêndio da renda nacional pode ser expressa como:

$$
\sum_{i=1}^{n-1}\left(a_{i n}+a_{\hat{i n}}\right) a_{n i}=1
$$

Diferentemente da literatura econômica que comumente toma o equilíbrio do Balanço de Pagamentos pelos coeficientes de preço, em Araújo e Lima (2007) tal equilíbrio é dado pelos coeficientes de trabalho, de tal forma que pode ser expresso como:

$$
\sum_{i=1}^{n-1}\left(\zeta a_{i \hat{n}}+a_{\hat{\imath} n}\right) a_{n i}=0
$$

A solução do sistema é tal que a quantidade total do bem comercializável produzido é dada pela soma das demandas doméstica e externa do bem analisado. Para quantidades físicas, sendo $X_{i}$ a quantidade produzida do bem $i$ e $X_{n}$ a população, ambos do país U, a solução do sistema é expressa por:

$$
X_{i}=\left(a_{i n}+\zeta \quad\right) X_{n}, i=1,2, \ldots, n-1
$$

Admitido que $p_{i}$ e $w_{u}$ como sendo o preço da mercadoria $i$ e a taxa de salário no país U, o conjunto de solução para o preço é dado por: 


$$
p_{i}=a_{n i} w_{u}, i=1,2, \ldots, n-1
$$

Definido o preço, será o paralelo entre os preços internos do bem $i$ entre os países $\mathrm{U}$ e A que vai determinar a vantagem comparativa na produção de tal bem, de tal forma que, se $p_{\hat{\imath}} \leq p_{i}$, o país U não apresentará vantagem comparativa em produzir o bem $i$ e, consequentemente, a demanda externa pelo bem $i$ é igual a zero. De forma análoga, se $p_{\hat{\imath}}>p_{i}$ a demanda externa pelo bem $i$ passa a ser representada pela função de exportação. Cabe ressaltar que tal cenário não exclui a possibilidade do país U continuar produzindo o bem $i$ em questão. Tendo isto em vista, sendo $\hat{x}_{i n}$ a demanda externa pelo bem $i, \eta_{i}$ a elasticidade-preço da demanda por exportações do bem $i$ ( $\eta_{i}<0$ ), $\beta_{i}$ a elasticidade-renda da demanda por exportações e, $Y_{A}$ a renda nacional do país $\mathrm{A}$, temos que as relações da demanda externa pelo bem $i$ são representadas como:

$$
x_{i \hat{n}}=\left\{\begin{array}{c}
0 \quad \text { se } p_{\hat{\imath}}<p_{i} \\
\left(\frac{p_{i}}{\hat{p}_{i}}\right)^{\eta_{i}} Y_{A}^{\beta_{i}} \text { se } \quad p_{\hat{\imath}} \geq p_{i}
\end{array}\right.
$$

Dividindo ambos os lados da Equação 6 pela população total do país A: $X_{\hat{n}}$, obtém-se o coeficiente per capita da demanda externa pela mercadoria $i$, onde $y_{A}$ é a renda per capita do país A:

$$
a_{i \hat{n}}=\left\{\begin{array}{c}
0 \quad \text { se } \hat{p}_{i}<p_{i} \\
\left(\frac{p_{i}}{p_{\hat{\imath}}}\right)^{\eta_{i}} y_{A}^{\beta_{i}} X_{\hat{n}}^{\beta_{i}-1} \text { se } \hat{p}_{i} \geq p_{i}
\end{array}\right.
$$

De forma análoga, a função de demanda por importação do bem $i$ é válida para $p_{i}>p_{\hat{\imath}}$; por outro lado, se o país A não apresenta vantagem comparativa em produzir o bem $\mathrm{i}: p_{i} \leq p_{\hat{\imath}}$, a demanda per capita do país A pelo bem $i$ do país $\mathrm{U}$ é zero. Logo, sendo a elasticidade-preço da demanda por importações do bem $i$ dado por $\Psi_{i}$, a elasticidade-renda da demanda por importações dada por $\varphi_{i}$ e a renda real do país $\mathrm{U}$ por $Y_{u}$, o coeficiente de importação pelo bem $i$ passa a ser dado como:

$$
a_{\hat{\imath} n}=\left\{\begin{array}{cc}
0 & \text { se } p_{i}<p_{\hat{\imath}} \\
\left(\frac{p_{\hat{\imath}}}{p_{i}}\right)^{\Psi_{i}} Y_{U}^{\varphi_{i}} X_{n}^{\varphi_{i}-1} \text { se } p_{i} \geq p_{\hat{\imath}}
\end{array}\right.
$$

A taxa de crescimento per capita da demanda por exportações do bem $i$, quando $p_{\hat{\imath}}>p_{i}$, pode ser obtida a partir da Equação 7 aplicando o logaritmo natural e diferenciando em relação ao tempo. Satisfazendo: $\frac{\dot{p}_{\hat{\imath}}}{p_{i}}=\sigma_{i}^{U}, \frac{\dot{p}_{i}}{p_{\hat{\imath}}}=\sigma_{i}^{A}, \frac{\dot{y}_{A}}{y_{A}}=\sigma_{y}^{A} \mathrm{e} \frac{\dot{X}_{\widehat{n}}}{X_{\widehat{n}}}=\hat{g}$, esta taxa passa a ser definida como: 


$$
\frac{\dot{a}_{i \widehat{n}}}{a_{i \hat{n}}}=\left\{\begin{array}{c}
0 \quad \text { se } p_{\hat{\imath}}<p_{i} \\
\eta_{i}\left(\sigma_{i}^{U}-\sigma_{i}^{A}\right)+\beta_{i} \sigma_{y}^{A}+\left(\beta_{i}-1\right) \hat{g} \text { se } p_{\hat{\imath}} \geq p_{i}
\end{array}\right.
$$

Da mesma forma, a taxa de crescimento per capita da demanda por importações do bem $i$, para $p_{i}>p_{\hat{\imath}}$, é obtida a partir do logaritmo e da diferenciação em relação ao tempo da Equação 8. Se $\frac{\dot{y}_{U}}{y_{U}}=\sigma_{y}^{U}$ e $\frac{\dot{x}_{n}}{X_{n}}=g$, temos que:

$$
\frac{\dot{a}_{\hat{\imath} n}}{a_{\hat{\imath} n}}=\left\{\begin{array}{c}
0 \quad \text { se } p_{i}<p_{\hat{\imath}} \\
\Psi_{i}\left(\sigma_{i}^{A}-\sigma_{i}^{U}\right)+\varphi_{i} \sigma_{y}^{U}+\left(\varphi_{i}-1\right) g \text { se } p_{i} \geq p_{\hat{\imath}}
\end{array}\right.
$$

Supondo que a taxa de variação do preço do bem $i$ seja igual entre os países, ou seja, $\sigma_{y}^{A}=\sigma_{y}^{U}$, e que $g=\hat{g}=0$, isto garante que a população entre ambos os países seja constante; o que permite reduzir as Equações 9' e 10’:

$$
\begin{aligned}
& \frac{\dot{a}_{i \widehat{n}}}{a_{i \widehat{n}}}=\beta_{i} \sigma_{y}^{A} \\
& \frac{\dot{a}_{\hat{\imath} n}}{a_{\hat{\imath} n}}=\varphi_{i} \sigma_{y}^{U}
\end{aligned}
$$

Tendo em vista o equilíbrio na balança de pagamentos, a taxa de variação da Equação 3 é igual a zero, de tal forma que:

$$
\sum_{i=1}^{n-1}\left(\zeta \dot{a}_{i \hat{n}}-\dot{a}_{\hat{\imath} n}\right) a_{n i}+\sum_{i=1}^{n-1}\left(\zeta a_{i \hat{n}}-a_{\hat{\imath} n}\right) a_{n i}=0
$$

Como o modelo desconsidera a existência de progresso tecnológico, ou seja: $\dot{a}_{i n}(t)=0$; a Equação 13 é reescrita como:

$$
\sum_{i=1}^{n-1}\left(\zeta \dot{a}_{i \hat{n}}-\dot{a}_{\hat{\imath} n}\right) a_{n i}=0
$$

Substituindo as Equações 11 e 12 na Equação 14:

$$
\sigma_{y}^{U}=\frac{\sum_{i=1}^{n-1} \xi \beta_{i} a_{i \widehat{n}} a_{n i}}{\sum_{i=1}^{n-1} \varphi_{i} a_{\hat{\imath} n} a_{n i}} \sigma_{y}^{A}
$$

A partir da Equação 11, temos que: 


$$
\sigma_{y}^{A}=\frac{\sum_{i=1}^{n-1} \frac{\dot{a}_{i \widehat{n}}}{a_{i \widehat{n}}}}{\sum_{i=1}^{n-1} \beta_{i}}
$$

Substituindo a Equação 16 na Equação 15:

$$
\sigma_{y}^{U}=\frac{\sum_{i=1}^{n-1} \xi \beta_{i} a_{i \widehat{n}} a_{n i}}{\left(\sum_{i=1}^{n-1} \varphi_{i} a_{\hat{i n}} a_{n i}\right)\left(\sum_{i=1}^{n-1} \beta_{i}\right)} \sum_{i=1}^{n-1} \frac{\dot{a}_{i \widehat{n}}}{a_{i \widehat{n}}}
$$

Finalmente, a Equação 17 denota a versão Multisetorial da Lei de Thirlwall (1979) desenvolvida por Araújo e Lima (2007), na qual a taxa de crescimento per capita do país U é diretamente proporcional à taxa de crescimento das exportações, de tal forma que a demanda por importações apresenta elasticidade negativa, e por exportações, positiva. As elasticidades são dadas pelo coeficiente que mensura a participação de cada setor no total das exportações e das importações.

Na LT, a taxa de crescimento do país se eleva quando a taxa de crescimento da renda do resto do mundo aumenta ou diante de mudanças nas elasticidades. Por outro lado, a LTM avança nas conclusões ao observar que uma mudança na composição da demanda ou na estrutura produtiva que implique na mudança da participação de cada setor no total importado e exportado também é relevante para determinar o crescimento. Ou seja, na análise Multisetorial, o país pode apresentar elevação na taxa de crescimento da renda mesmo quando a taxa de crescimento da renda do mundo não ocorrer, o que está condicionado à alteração na composição setorial das exportações e/ou importações de tal país.

As evidências empíricas constataram que diferentes composições setoriais resultam em diferentes taxas de crescimento de longo prazo, ou seja, que o crescimento econômico é compatível com a restrição externa da balança de pagamentos do ponto de vista Multisetorial. Estas constatações em torno da LTM são desdobramentos de diferentes metodologias empregadas que merecem ser sublinhadas junto aos principais resultados encontrados na literatura econômica. Em suma, os trabalhos elevaram a restrição externa enquanto um importante elemento para explicar o crescimento econômico da amostra analisada. Neste contexto, resultados semelhantes são observados para o Brasil quanto à unidade de observação dos testes empíricos quando comparados com uma amostra maior de unidades de observação.

Para o caso brasileiro, Carbinato (2010), utilizando o Vetor de correlação de erro (VEC) e Ordinary Least Squares (OLS), atestou a validade da LTM para 
o Brasil entre 1962 e 2006 e, sobretudo, averiguou que os setores de maior intensidade tecnológica apresentam maior elasticidade-renda e participação relativa no comércio internacional. Complementar a estes resultados, Soares e Teixeira (2012) ${ }^{2}$ observaram que, na maioria dos casos, é válida a hipótese de exportações impulsionadas pelo crescimento externo ${ }^{3}$, e que a estimação das elasticidades setoriais tem papel relevante na compreensão do padrão recente do desenvolvimento brasileiro. Além disto, apesar de alterações recentes, o Brasil ainda mantém um padrão de importação de produtos de maior intensidade tecnológica e, em contrapartida, exporta produtos com menor valor agregado.

Alguns estudos, entretanto, apontam certas divergências. Queiroz (2011), ao utilizar o Vetor Autorregressivo (VAR) e VEC, observou que a LTM se mostrou como um bom estimador do crescimento real da economia. No período analisado, de 1962 a 2008, o processo de crescimento brasileiro é restringido pelo balanço de pagamentos, e não foram observadas mudanças estruturais relevantes no país. Estes resultados destoam de Gouvêa e Lima (2010), os quais utilizaram o VEC entre o período de 1962 e 2006, ao observarem que de 1962 a 1965 elevou-se a relação entre as elasticidades-renda da exportação e da importação que, dada a alteração estrutural do comércio, reduziu a restrição externa do país; porém, tal processo é revertido após 1965.

A validade da LTM no Brasil também é sublinhada por Romero, Silveira e Jayme (2011), os quais utilizaram o procedimento de cointegração de Johansen no período de 1962 a 2006, e mostram que a trajetória do crescimento observado é semelhante ao do crescimento calculado. Esta mesma constatação foi observada por Gouvêa (2010), que trabalhou numa amostra de 90 países entre 1962 e 1999.

Em consonância, quando ampliada a amostra de países, as constatações empíricas chegam a conclusões semelhantes quanto à aplicação da LTM, inclusive no que diz respeito às maiores elasticidades-renda nos setores de maior intensidade

2 Para chegar a essas conclusões, os autores se sustentaram numa amostra de 1980 a 2011 com dados trimestrais e outra, de 1996 a 2010, com dados anuais.

3 Complementarmente a esta observação, Romero et al. (2011) observaram, via análise de cointegração, função impulso-resposta e decomposição dos erros para o Brasil entre 1962 e 2010, que um choque exógeno nas importações apresenta um reduzido efeito sobre as demais variáveis do modelo da LTM; que choques na taxa de câmbio real têm efeito significativo sobre as importações, e que choques sobre as exportações têm efeitos pouco significativos sobre a renda externa e a taxa de câmbio real. 
tecnológica ${ }^{4}$ (Romero et al., 2011; Gouvêa, 2010; Cimoli, Porcile \& Rovira, 2010; Gouvêa \& Lima, 2010; Romero \& McCombie, 20155).

No seu levantamento bibliográfico, cruzando com os resultados encontrados, Romero e McCombie (2015) elucidam estas convergências das evidências empíricas em torno da LTM, bem como a validade da lei para os países investigados.

Gouvêa e Lima (2010) analisaram uma amostra de oito países, quatro latino-americanos e quatro asiáticos, no período de 1962 a 2006. Os autores estimaram a correção de erro vetorial para obter as elasticidades-renda e preço, as quais permitiram concluir que a composição setorial das exportações e importações importa para o crescimento. Além disto, a metodologia adotada permitiu, também, capturar o impacto da mudança estrutural nas elasticidades-renda e, consequentemente, no crescimento. A composição setorial das exportações e importações em determinar a restrição externa das economias também está entre os leques de conclusões do painel pelo método de efeitos fixos de Gouvêa (2010), que trabalhou numa amostra de 90 países entre 1962 e 1999; e Cimoli et al. (2010) com a amostra de 29 países desenvolvidos e subdesenvolvidos.

Cabe ainda ressaltar que as mudanças estruturais ${ }^{6}$ foram importantes para os países em desenvolvimento que apresentaram tendência de convergência de renda para estratos de renda mais elevada, ao ampliar a participação dos setores com maiores elasticidades-renda da demanda por exportações em relação à elasticidade-renda da demanda por importações (Cimoli et al., 2010).

Ao estabelecer um paralelo do ponto de vista metodológico com o referencial abordado, como sublinhado por Romero e McCombie (2015), e ao estimar este trabalho as elasticidades usando dados em painel, têm-se resultados mais confiáveis ${ }^{7}$. O que se deve, em parte: i) por oferecer respaldo estatístico e econométrico, munindo de maior credibilidade dado seu maior rigor metodológico; e ii) por

4 Apesar de não explorar os diferentes níveis tecnológicos que compõem a manufatura, a regressão de Tharnpanich e McCombie (2013) atribuiu elasticidades de renda mais altas aos produtos manufaturados em detrimento dos produtos primários.

5 Romero e McCombie (2015) utilizam duas metodologias para um grupo de quatorze países: VEC com índices de preços agregados e painéis de produtos cruzados com índices de preços no nível do produto. Dados os resultados encontrados, a segunda estratégia de estimativa permitiu gerar resultados consideravelmente mais confiáveis e menos voláteis.

6 Em Cimoli et al. (2010), tais mudanças estruturais se concentraram nos bens com maiores características técnicas e de maior qualidade.

7 Apesar de que aqui optamos por não trabalhar com índices de preços no nível do produto. 
permitir controlar outras variáveis não observáveis que podem afetar de forma heterogênea as funções setoriais de exportação e importação (Duarte, Lamounier \& Takamatsu, 2007; Gouvêa \& Lima, 2013). Além disto, para o nível agregado, ao estimar por GMM-Sistema e incluir a variável dependente defasada entre as explicativas, o modelo permite captar dependência temporal das exportações e importações, ou seja, o seu efeito dinâmico no modelo, algo ainda pouco explorado na literatura.

Apesar de concluir em seu artigo que, desde o desenvolvimento da LT, uma série de críticas foram tecidas em torno do modelo de crescimento restrito pelo balanço de pagamentos ${ }^{8}$, McCombie (2011) atesta a relevância desta literatura para explicar as diferentes taxas de crescimento na economia. $\mathrm{O}$ avanço da literatura a partir da primeira versão da LT e os testes empíricos corroboram esta conclusão. É por isto que as críticas em torno, por exemplo, da consistência e da falácia da composição não invalidaram os principais insights deste instrumento para a análise do crescimento. Em síntese, o crescimento de muitos países mantém relação com o desempenho econômico dos mercados externos e é limitado pelo seu balanço de pagamentos.

\section{METODOLOGIA}

Visando estimar as elasticidades setoriais das exportações e das importações a partir da LTM, foi utilizado o estimador de dados em painel dinâmico (GMM-Sistema) ${ }^{9}$. Desta forma, a partir dos coeficientes estimados, foi possível identificar os setores econômicos com maior potencial de crescimento diante da estratégia de inserção do comercial internacional, bem como averiguar se o crescimento foi restrito pelo balanço de pagamentos. Cabe ressaltar que as elasticidades estimadas correspondem à média dos atuais países da amostra. Ou seja, por se tratar de um grupo de países bastante heterogêneo, os valores das elasticidades apresentadas não devem ser interpretados isoladamente para um determinado país.

A validade do modelo foi testada por duas vias, primeiro conforme McCombie (1989), que propôs a comparação entre as elasticidades-renda das importações estimada e hipotética, de forma a estabelecer um paralelo entre a taxa de crescimento observada e a compatível com o equilíbrio externo; e, segundo, pela regres-

8 Ver McCombie (2011).

9 Estimar por dados em painel permite controlar as características não observáveis da variável escolhida e corrigir problemas de variáveis omitidas (Wooldridge, 2002). 
são entre tais taxas, técnica comumente utilizada nesta literatura quando a amostra é um grupo de países.

O modelo desenvolvido permite analisar os efeitos supostamente separados das variáveis explicativas, visando identificar a importância relativa de cada uma delas sobre a variação da renda per capita média, no período considerado (20002013) nos $69^{10}$ países de renda média.

O critério de determinação de renda média está de acordo com a classificação do Rendimento Nacional Bruto do Banco Mundial ${ }^{11}$, no qual as economias de renda média baixa situam-se no intervalo de renda de US\$ 1046 a US\$ 4125, e economias de renda média elevada, no intervalo de US\$ 4126 a US\$ $12745^{12}$.

\section{II.1. Dados e variáveis}

Neste trabalho, os dados são anuais, todas as variáveis monetárias estão em dólares (US\$), e os valores reais foram deslocados para o ano base de 2005. O período de análise compreende o intervalo 2000-2013, estrategicamente selecionado a fim de captar o boom dos preços internacionais das commodities.

As exportações e importações dos países de renda média para o resto do mundo foram extraídas do Common format for Transient Data Exchange (COMTRADE), sendo que a classificação utilizada agrega os produtos a partir do sistema internacional SITC - Revisão 2 e desagregação a três dígitos. Posteriormente, a

10 Albânia (ALB), Argélia (ARG), Argentina (ARG), Azerbaijão (AZE), Belarus (BEA), Belize (BEI), Botswana (BOT), Brasil (BRA), Bulgária (BUL), Colômbia (COL), Costa Rica (COS), Dominica (DOM), República Dominicana (REP), Equador (QUE), Fiji (FIJ), Gabão (GAB), Granada (GRA), Hungria (HUN), Irã (IRN), Iraque (IRQ), Jamaica (JAM), Jordan (JOR), Cazaquistão (CAZ), Líbia (LIB), Malásia (MAS), México (MEX), Panamá (PAN), Peru (PER), România (ROM), Sérvia (SER), Seicheles (SEI), África do Sul (AFS), Santa Lucia (SAL), São Vincent e Granadinas (SVG), Suriname (SUR), Tailândia (TAI), Tonga (TON), Tunísia (TUN), Turquia (TUR), Armênia (ARM), Bolívia (BOL), Camarão (CAR), Congo (COM), Costa do Marfim (COM), Egito (EGI), El Salvador (ELS), Geórgia (GEO), Gana (GAN), Guatemala (GUA), Honduras (HON), Indonésia (IND), Quirguistão (QUI), Lesoto (LES), Mauritânia (MAU), Mongólia (MON), Marrocos (MAR), Nicarágua (NIC), Nigéria (NIG), Paquistão (PAQ), Papua-Nova Guiné (PNG), Paraguai (PAR), Filipinas (FIL), Senegal (SEM), Sri Lanka (SRL), Síria (SIR), Ucrânia (UCR), Vietnã (VIE); Iêmen (IEM), Zâmbia (ZAM).

11 Ver a metodologia de classificação do Banco Mundial em: http://data.worldbank.org/about/country-and-lending-groups

12 Do total de países de renda média (média baixa e média elevada), foram excluídos da amostra os países para os quais não se dispunha de dados para as estimativas; além dos outliers China e Índia. 
classificação dos bens em setores (níveis tecnológicos) está de acordo com Lall (2002). Tal especificação possibilita separar as atividades em diferentes níveis de complexidade tecnológica utilizando a mesma categoria de produto (Quadro 1) ${ }^{13}$, a partir de dois eixos: i) as taxonomias de Pavitt (1984), que possibilitam distinguir os produtos baseados em recursos, utilização intensiva de mão de obra, manufatura diferenciada e baseada em ciência; e ii) OCDE (1994) que fornece uma classificação mais detalhada com base na atividade tecnológica dentro de cada categoria.

Quadro 1. Classificação de Lall (2000)

\begin{tabular}{ll}
\hline \multicolumn{1}{c}{ Classificação } & \multicolumn{1}{c}{ Exemplos } \\
\hline Produtos primários & $\begin{array}{l}\text { Frutas frescas, carne, arroz, cacau, chá, } \\
\text { café, madeira, carvão, petróleo bruto, gás. }\end{array}$ \\
\hline Produtos manufaturados & \\
\hline
\end{tabular}

$\underline{\text { Recursos baseados em manufatura }}$

Produtos agroflorestais

Carnes / frutas, bebidas, produtos de madeira, óleos vegetais.

Concentrados de minério, petróleo / produ-

Outros produtos tos de borracha, cimento, pedras lapidadas, vidro.

Manufaturas de baixa tecnologia

Têxtil / grupos de moda

Tecidos têxteis, vestuário, chapelaria, calçado, manufaturas de couro, artigos de viagem.

Outras tecnologias baixas

Cerâmica, peças / estruturas metálicas simples, fumites, joalharia, brinquedos, produtos de plástico.

13 De acordo com Lall (2000), esta classificação do comércio externo apresenta duas limitações inerentes à decomposição por nível tecnológico: i) a produção de um determinado bem de maior complexidade tecnológica pode envolver processos de fabricação com distintas intensidades tecnológicas; ii) as denominadas “operações especiais” são excluídas da classificação. Fazem parte desta operação: corrente elétrica, cinema (filme), impressos, operações especiais, ouro, obras de arte, moedas e animais de estimação. 
Manufaturas de média intensidade

tecnológica

Produtos automotivos

Veículos de passageiros e peças, veículos comerciais, motocicletas e peças.

Processos industriais de média intensidade

Fibras sintéticas, produtos químicos e tintecnológica tas, fertilizantes, plásticos, ferro, tubos.

Indústrias de engenharia de média intensiMotores, maquinaria industrial, bombas, dade tecnológica comutadores, navios, relógios.

Manufaturas de alta intensidade tecnológica

Eletrônica e produtos elétricos

Office / processamento de dados / equipamento de telecomunicações, TVs, transistores, turbinas, equipamentos de geração de energia.

Outras tecnologias altas

Farmacêutica, aeroespacial, óptica / instrumentos de medição, câmeras.

Fonte: adaptado de Lall (2000).

O Quadro 2 apresenta a descrição das variáveis do modelo e os sinais esperados das estimativas. O modelo é replicado cinco vezes para as exportações e importações segundo o nível tecnológico considerado: produtos primários (PP), recursos baseados em manufatura (RB), baixa intensidade tecnológica (LT), média intensidade tecnológica (MT) e alta intensidade tecnológica (HT). Todas as variáveis do modelo, com exceção do câmbio real, estão em termos per capita.

Quadro 2. Descrição das variáveis do modelo

\begin{tabular}{lcccc}
\hline Variável & Sigla & Unidade & Fonte & Sinal esperado \\
\hline Dependente & & & & \\
Exportações & $e x_{i t}$ & US\$ & COMTRADE \\
Importações & $i m_{i t}$ & US\$ & COMTRADE \\
\hline
\end{tabular}

Explicativa 


\begin{tabular}{lccccc} 
Exportações defasadas & $e x_{i t-1}$ & US\$ & COMTRADE & + \\
\hline $\begin{array}{l}\text { Importações defasadas } \\
\text { Renda per capita doméstica }\end{array}$ & $g d m_{i t-1}$ & US\$ & COMTRADE & + \\
$\begin{array}{l}\text { Renda per capita do resto do } \\
\text { mundo }\end{array}$ & $g d p w_{i}$ & US\$ & BM & + \\
\hline $\begin{array}{l}\text { Taxa real de câmbio } \\
\text { Rend }\end{array}$ & UD/ US\$ & FMI e BM & $+\left(X_{i t}\right)$ ou - $\left(M_{i t}\right)$ \\
\hline
\end{tabular}

Fonte: elaboração dos autores, onde 'UD’ corresponde à moeda da unidade doméstica, ou seja, à unidade de observação, memorando que todas as variáveis monetárias estão em valores constantes de 2005.

Os índices de preços internacionais das commodities foram obtidos no FMI. O Índice de Preço ao Atacado dos Estados Unidos da América (EUA) foi utilizado como proxy do índice de preço internacional para inflacionar os preços internacionais das commodities para o ano base de 2005.

As demais variáveis do modelo foram extraídas do World Development Indicators do World Bank (BM): Produto Interno Bruto doméstico e do resto do mundo, produto interno bruto per capita doméstico e do resto do mundo ${ }^{14} \mathrm{e}$ a taxa de câmbio real. A taxa de Câmbio Real foi construída como sendo o produto entre a taxa de câmbio oficial média (moeda local/dólares) e a razão entre o Índice de Preço ao Atacado (IPA) dos EUA e o Índice de Preço ao Consumidor local (IPC), com ano base em 2005. Tal relação pode ser expressa como: .

Por conveniência, serão adotadas as seguintes abreviações: $p p \_x$ e $p p \_m$ são as exportações e importações per capita de produtos primários, respectivamente; $r b \_x$ e $r b \_x$ são as exportações e importações per capita de bens de recursos baseados em manufatura, respectivamente; $l t \_x$ e $l t \_m$ são as exportações e importações per capita de bens de baixa intensidade tecnológica, respectivamente; $m t \quad x$ e $m t \_m$ são as exportações e importações per capita de bens de média intensidade tecnológica, respectivamente e; $h t \_x$ e $h t \_m$ são as exportações e importações per capita de bens de alta intensidade tecnológica, respectivamente.

14 Não há consenso na literatura econômica da variável a ser utilizada para 'renda do resto do mundo'. Apesar da possibilidade da substituição desta variável stricto sensu (Hussain, 1999), neste trabalho optou-se pela somatória da renda individual de cada país. 


\section{II.2. Modelo de dados em painel}

O modelo de dados em painel é caracterizado pelo uso combinado de séries de tempo (time-series) com cortes seccionais (cross-sections). Seguindo a apresentação e notação de Baum (2006), a descrição geral do modelo é tal que o subscrito $i$ representa a unidade de observação e o subscrito $t$ o período de tempo correspondente, de tal forma que a amostra passa a compor com T observações temporais para cada um dos $\mathrm{N}$ indivíduos.

Os dados em painel apresentam vantagens em relação ao uso específico do corte transversal ou de séries temporais ${ }^{15}$. A metodologia adotada, GMM-Sistema, permite incorporar a presença da variável dependente defasada entre as variáveis explicativas. A justificativa para isto está associada ao fato de que muitas séries econômicas se relacionam uma com as outras e com seus valores em períodos passados. Neste caso, a inclusão da variável dependente defasada, enquanto uma variável explicativa, fornece estimadores não viesados.

O painel dinâmico GMM-Diferença, desenvolvido por Arellano e Bond (1991), trata o problema de endogeneidade com a técnica de variáveis instrumentais ${ }^{16}$. A partir daí, o método do GMM-Sistema, resultado dos trabalhos de Arellano-Bover (1995) e Blundell-Bond (1998), consiste em um sistema de duas equações: i) na equação em diferença, as variáveis em diferença são instrumentalizadas com suas defasagens disponíveis em nível; ii) na equação em nível, as variáveis em nível são instrumentalizadas com defasagens de suas primeiras diferenças. Ressalta-se que as diferenças das variáveis instrumentalizadas e os efeitos fixos individuais são não correlacionados.

Definida a modelagem econométrica, as variáveis que compõem as estimativas são: exportações (ex), importações (im), renda per capita do mundo ( $g d p w$ ), renda per capita da unidade de observação $(g d p)$ e taxa de câmbio real (rer). As equações abaixo são referentes às funções de exportações e importações:

$$
\begin{gathered}
\Delta \ln \left[\operatorname{ex}_{j i t}\right]=\beta_{1} \Delta \ln \left[\operatorname{ex}_{j i t-1}\right]+\beta_{2} \Delta \ln \left[g d p w_{i t}\right]+\beta_{3} \Delta \ln \left[\operatorname{rer}_{i t}\right]+\mu_{j i t} \\
\Delta \ln \left[i m_{j i t}\right]=\beta_{1} \Delta \ln \left[i m_{j i t-1}\right]+\beta_{2} \Delta \ln \left[g d p_{i t}\right]+\beta_{3} \Delta \ln \left[\text { rer }_{i t}\right]+\mu_{J i t}
\end{gathered}
$$

15 Ver Baltagi (2005).

16 Ver Baltagi (2005). 
Onde o subscrito $i$ representa as unidades de observação: países de renda média; o subscrito $t$ é o período observado: $t=2000,2001, \ldots, 2013$; o subscrito $j$ são os setores de intensidade tecnológica de acordo com a classificação de Lall (2000): $j$ para bens primários, $j \quad$ para bens manufaturados, $j$ para bens manufaturados de baixa intensidade tecnológica, $j$ para bens manufaturados de média intensidade tecnológica, e $j$ para bens manufaturados de alta intensidade tecnológica. Os parâmetros $\beta_{1}, \beta_{2}, \beta_{4}, \beta_{5}$ e $\beta_{5}$ a serem estimados para cada setor $j$ são, respectivamente, a variável explicativa defasada em um período das exportações, as elasticidades-renda e preço da demanda por exportações, e a variável explicativa defasada em um período das importações e as elasticidades-renda e preço da demanda por importações. E, $\mu_{j i t}$ é o termo de erro idiossincrático.

Nos resultados das estimativas, Tabelas 1 e 2 , complementarmente às estimativas do modelo, também serão apresentados o teste de Arellano \& Bond (arlp) corresponde ao teste de autocorrelação para correlação de primeira ordem para as diferenças dos erros do modelo; da mesma forma, Arellano \& Bond ( $a r 2 p$ ) é o teste de autocorrelação para correlação de segunda ordem para as diferenças dos erros do modelo. Os valores dos testes Arellano \& Bond ( $a r 1 p)$, Arellano \& Bond ( $a r 2 p)$ e do Teste de Hansen se referem aos p-valores correspondentes às estatísticas de teste. Nas estimativas, também foi utilizada a opção collapse do comando xtabond 2 do STATA a fim de mitigar a quantidade de instrumentos das estimativas.

A metodologia descrita é válida, também, para a estimação das elasticidades-renda individuais para a amostra de quinze países, entretanto, tratar-se-á de um painel cross-product. Neste caso, nas Equações 18 e 19, o subscrito $i$ indica o produto comercializado no setor de intensidade tecnológica, $j$.

\section{ANÁLISE DOS RESULTADOS}

A análise da evolução dos preços internacionais das commodities pode ser segmentado em dois momentos desde a década de 1980 (Bassos, 2014; Veríssimo \& Xavier, 2013; Brandão, 2011). Como ilustrado no Gráfico $1^{17}$, no primeiro momento, até o ano de 2000, os preços não apresentam uma trajetória clara, apesar de que na década de 90, salvo PBEVE, as oscilações são modestas. No segundo período, que se dá a partir do ano de 2000, tem início uma tendência de elevação dos preços ${ }^{18}$, onde cabem duas observações: i) a queda dos preços das commodities

17 O período de análise se restringe à disponibilidade de dados para as commodities selecionadas.

18 Os objetivos deste trabalho não incluem avaliar as causas da oscilação dos preços das commodities. 
em 2008/2009 devido à crise econômica internacional, que não impediu que os preços se mantivessem em níveis relativamente elevados e; ii) a partir de meados de 2009, os preços voltaram a apresentar tendência de elevação até 2014.

Cumpre ressaltar, como será apresentado nas Tabelas 4 e 5, da amostra de quinze países, que a participação conjunta nas exportações de produtos primários e produtos baseados em recursos manufaturados (ver Quadro 1), são relevantemente compostos por commodities. Quanto ao volume importado, a participação de produtos de média e alta intensidade tecnológica destaca-se. Esta conclusão ainda é verídica quando se toma a média da amostra de 69 países $^{19}$.

\section{Gráfico 1. Índice de preços internacionais de commodities $(2005$ = 100)}

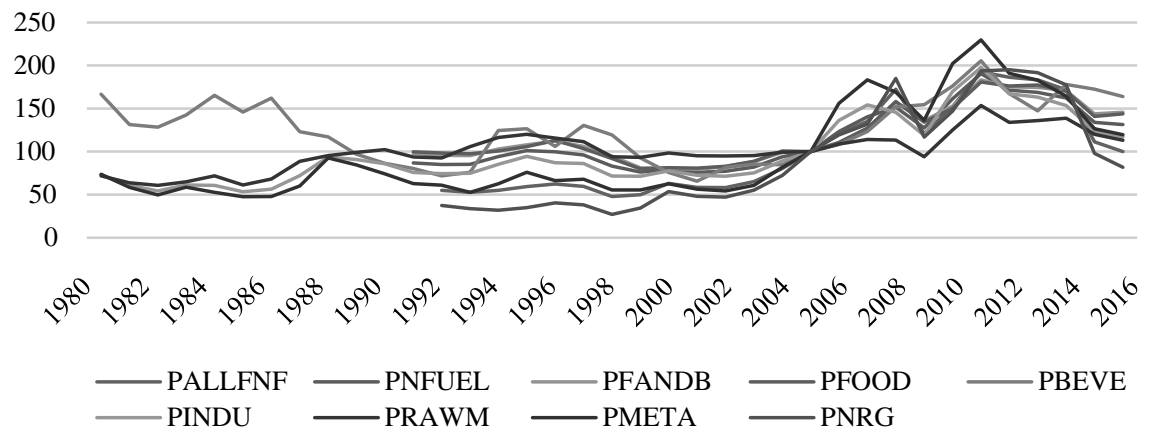

Nota: O valor observado em cada ano diz respeito à sua média mensal, expresso em US\$ com valor real referente ao ano de 2005. PALLFNF: todos os índices de preços de commodities (inclusive índices de preços de combustível e não-combustível); PNFUEL: índice de preços de não-combustíveis (inclui índices de preços de alimentos, bebidas e insumos industriais); PFANDB: índice de preços de alimentos e bebidas; PFOOD: índice de preços de alimentos; PBEVE: Índice de Preços de Bebidas; PINDU: índice de preços de insumos industriais; PRAWM: índice de matérias-primas agrícolas; PMETA: índice de preços de metais; PNRG: índice de combustível - Energia (inclui os índices de preço do petróleo bruto, gás natural e carvão). Fonte: elaboração dos autores a partir dos dados do FMI.

Entretanto, vale salientar alguns dos elementos explicativos para esta mudança de comportamento, quais sejam: a elevação da população mundial, os desdobramentos do crescimento econômico chinês, o crescimento do produto econômico e urbanização, e o aumento do preço do petróleo com seus desdobramentos sobre os custos de produção e transporte (Brandão \& Alvez, 2007; Brandão, 2011; Maluf \& Speranza, 2013).

19 Dada a limitação de espaço, a desagregação e participação percentual de cada bem na classificação de Lall (2000) para toda a amostra de 69 não será apresentada. Caso haja interesse em tais dados, solicite os autores. 
III.1. Estimativas das funções de demanda para a amostra de 69 países

As funções de demanda por exportações e importações setoriais, estimadas a partir das Equações 23 e 24, são os parâmetros que determinam a intensidade da restrição externa da LTM.

Salvo a exceção das elasticidades-preço das exportações, que não apresentaram significância estatística, todas as demais estimativas das elasticidades apresentaram o sinal esperado: positivo para as elasticidades-renda das exportações e importações e negativo para a elasticidade-preço das importações.

Os resultados, dispostos nas Tabelas 2 e 3, permitem concluir que a inclusão das variáveis dependentes defasadas em um período nas estimativas ${ }^{20}$, e , permitem captar o efeito dinâmico no modelo, de tal forma que as exportações e importações mostraram-se persistentes no tempo, ou seja, as exportações no período $t$ tendem a influenciar positivamente as exportações no período $t+1$; análogo ao caso das importações.

Dada a metodologia, o tratamento estatístico das variáveis e a amostra de países selecionada, as exportações mostraram-se mais sensíveis às variações percentuais da renda per capita do resto do mundo, quando comparadas às variações percentuais das importações dadas as variações percentuais na renda per capita doméstica. Cabe ainda ressaltar que os setores de maior intensidade tecnológica tendem a apresentar elasticidades-renda das exportações maiores, o mesmo sendo válido para as importações, salvo o setor RB. Isto permite concluir que, se a amostra de países concentra suas exportações nos setores de maior intensidade tecnológica, ela tende a usufruir de maior renda das exportações e, portanto, de um maior crescimento econômico diante de cenários de elevação da renda mundial. Por outro lado, tendo em vista as elasticidades-renda das importações, se a amostra concentra suas importações nos setores de maior intensidade tecnológica, mediante um cenário de elevação da renda doméstica, ela apresenta remessa de divisas mais intensa para o resto do mundo, o que impacta, negativamente, no crescimento econômico.

Na Tabela 1, as elasticidades-renda das exportações mostraram-se elásticas em todos os setores, indicando que uma elevação de 1\% na renda per capita mundial eleva mais que proporcionalmente as exportações médias dos países da amostra.

20 As inclusões das variáveis dependentes defasadas geraram elasticidades inelásticas menores que a unidade, o que permite observar que tal inclusão não é explosiva no modelo estimado. 
Tabela 1. Elasticidade-renda das Exportações (setorial)

\begin{tabular}{|c|c|c|c|c|c|}
\hline & $\mathrm{PP}$ & $\mathrm{RB}$ & $\mathrm{LT}$ & MT & HT \\
\hline$\Delta \ln \left[e x_{i t-1}\right]$ & $\begin{array}{c}.866^{* * * *} \\
(.088)\end{array}$ & $\begin{array}{c}.694^{* * *} \\
(.091)\end{array}$ & $\begin{array}{c}.546 * * * \\
(.166)\end{array}$ & $\begin{array}{c}.590 * * * \\
(.081)\end{array}$ & $\begin{array}{c}.638 * * * \\
(.132)\end{array}$ \\
\hline$\Delta \ln \left[g d p w_{i t}\right]$ & $\begin{array}{c}1.520 * * * \\
(.571)\end{array}$ & $\begin{array}{c}1.570 * * \\
(.647)\end{array}$ & $\begin{array}{c}2.510 * * \\
(1.061)\end{array}$ & $\begin{array}{c}2.965 * * * \\
(.950)\end{array}$ & $\begin{array}{c}3.095 * * \\
(1.364)\end{array}$ \\
\hline$\Delta \ln \left[\right.$ rer $\left._{i t}\right]$ & $\begin{array}{c}.032 \\
(.336)\end{array}$ & $\begin{array}{l}-.569 \\
(.541)\end{array}$ & $\begin{array}{l}0.678 \\
(.553)\end{array}$ & $\begin{array}{l}-.699 \\
(.650)\end{array}$ & $\begin{array}{l}.258 \\
(.679)\end{array}$ \\
\hline Constante & $\begin{array}{c}-13.835 * * * \\
(5.122)\end{array}$ & $\begin{array}{c}-11.915 * * \\
(7.328)\end{array}$ & $\begin{array}{c}-26.582 * * \\
(11.068)\end{array}$ & $\begin{array}{c}-24.210^{* * *} \\
(10.586)\end{array}$ & $\begin{array}{c}-30.073 * * \\
(14.102)\end{array}$ \\
\hline Obs. & 768 & 786 & 785 & 771 & 777 \\
\hline $\mathrm{n}^{\circ}$ de grupos & 68 & 69 & 69 & 67 & 67 \\
\hline Def. inst. & 3 & 3 & 3 & 3 & 3 \\
\hline$n^{\circ}$ inst. & 36 & 32 & 33 & 29 & 37 \\
\hline (ar1p) & .074 & .016 & .008 & .012 & .095 \\
\hline (ar2p) & .317 & .711 & .541 & .153 & .293 \\
\hline Teste Hansen & .402 & .133 & .192 & .760 & .110 \\
\hline
\end{tabular}

Notas: Os valores entre parênteses são os erros padrões robustos. *** $\mathrm{p}<.01$, ** $\mathrm{p}<.05$, * $\mathrm{p}<.1$. Fonte: elaboração dos autores a partir dos dados do COMTRADE, BM e FMI.

Na Tabela 2, são apresentadas as estimativas obtidas para as elasticidades-renda e o preço das importações. Como pode ser observado, a elasticidade-renda é inelástica, inferior à unidade, somente para o setor de PP, ou seja, a variação das importações neste setor é menos proporcional às variações na renda média doméstica. Para os demais setores, a relação mostrou-se elástica, com destaque para o setor de HT, de tal forma que uma elevação de $10 \%$ na renda doméstica eleva em $11.79 \%$ a importação por bens de alta intensidade tecnológica. Para a elasticidade-preço das importações, estatisticamente significativa para todos os setores, os resultados indicam que a valorização da moeda, considerando o efeito conjunto dos países selecionados na amostra, tende a elevar o valor importado. As importações nos setores de PP, RB e MT mostraram-se mais sensíveis às variações do câmbio. 
Além disso, para as estimativas das Tabelas 2 e 3, os testes de Arellano e Bond apontam para a rejeição da hipótese nula de ausência de autocorrelação de primeira ordem e aceitação da existência de autocorrelação de segunda ordem dos resíduos; e os valores-p do teste de Hansen permitem aceitar as hipóteses de que os instrumentos utilizados na estimação dos modelos são válidos ${ }^{21}$.

Tabela 2. Elasticidade-renda das importações (setorial)

\begin{tabular}{|c|c|c|c|c|c|}
\hline & $\mathrm{PP}$ & $\mathrm{RB}$ & LT & MT & HT \\
\hline$\Delta \ln \left[i m_{i t-1}\right]$ & $\begin{array}{c}.324^{* * *} \\
(.124)\end{array}$ & $\begin{array}{l}.343 * * \\
(.163)\end{array}$ & $\begin{array}{c}.469 * * * \\
(.129)\end{array}$ & $\begin{array}{c}.297 * * * \\
(.110)\end{array}$ & $\begin{array}{c}.401^{* * *} \\
(.148)\end{array}$ \\
\hline$\Delta \ln \left[g d p_{i t}\right]$ & $\begin{array}{l}.895 * * \\
(.469)\end{array}$ & $\begin{array}{c}1.576^{* *} \\
(.719)\end{array}$ & $\begin{array}{c}1.043^{* * *} \\
(.289)\end{array}$ & $\begin{array}{c}1.047^{* * * *} \\
(.284)\end{array}$ & $\begin{array}{c}1.179 * * * \\
(.349)\end{array}$ \\
\hline$\Delta \ln \left[\right.$ rer $\left._{i t}\right]$ & $\begin{array}{c}-1.709 * * * \\
(.358)\end{array}$ & $\begin{array}{c}-1.183^{* * *} \\
(.414)\end{array}$ & $\begin{array}{c}-.886 * * \\
(.365)\end{array}$ & $\begin{array}{c}-1.379 * * * \\
(.327)\end{array}$ & $\begin{array}{c}-.867^{*} \\
(.503)\end{array}$ \\
\hline Constante & $\begin{array}{c}4.129 \\
(4.039)\end{array}$ & $\begin{array}{l}-3.435 \\
(4.655)\end{array}$ & $\begin{array}{l}-1.549 \\
(3.074)\end{array}$ & $\begin{array}{c}2.127 \\
(2.271)\end{array}$ & $\begin{array}{c}-2.432 \\
(3.358)\end{array}$ \\
\hline Obs. & 731 & 763 & 765 & 763 & 775 \\
\hline $\mathrm{n}^{\circ}$ de grupos & 67 & 69 & 69 & 68 & 69 \\
\hline Def. inst. & 3 & 3 & 3 & 3 & 3 \\
\hline $\mathrm{n}^{\circ}$ inst. & 32 & 27 & 31 & 34 & 35 \\
\hline (ar1p) & .026 & .091 & .009 & .076 & .005 \\
\hline (ar2p) & .443 & .572 & .170 & .934 & .998 \\
\hline Teste Hansen & .231 & .281 & .203 & .254 & .178 \\
\hline
\end{tabular}

Notas: Os valores entre parênteses são os erros padrões robustos. ${ }^{* * *} \mathrm{p}<.01$, ${ }^{* *} \mathrm{p}<.05$, ${ }^{*} \mathrm{p}<.1$. Fonte: elaboração dos autores a partir dos dados do COMTRADE, BM e FMI.

A fim de verificar se, de fato, o crescimento dos atuais países de renda média esteve relacionado à disponibilidade de divisas entre 2000 e 2013, a interpretação proposta por Carvalho e Lima (2009) da metodologia desenvolvida por McCombie

21 As conclusões apresentadas anteriormente devem ser analisadas cautelosamente, uma vez que correspondem às estimativas para a média dos atuais países de renda média selecionados. Ou seja, por compor um grupo bastante heterogêneo de países, os valores das elasticidades apresentados não devem ser interpretados isoladamente, como representativo para um determinado país. 
(1989) pode ser empregada. Brevemente, McCombie (1989) propôs a comparação entre as elasticidades-renda estimadas e hipotéticas, de forma a estabelecer um paralelo entre a taxa de crescimento observada com a compatível com o equilíbrio externo. Ou seja, a proximidade entre as taxas de crescimento efetiva e a calculada a partir das estimativas das elasticidades-renda implica a validade do modelo (Carvalho \& Lima, 2009).

Tendo isto em vista, a taxa de crescimento médio entre 2000 e 2013 estimada pela LTM $^{22}$ foi de 2.21, enquanto a efetiva foi de 2.14. Constata-se, portanto, a proximidade entre ambas as taxas de crescimento, cujo erro de previsão foi 0.07. O teste t-Student, com valor igual a 0.139 , permite validar a LTM pela comparação entre ambas as taxas, dado que a estatística determina que a igualdade entre ambas as taxas não pode ser rejeitada.

Complementar ao teste anterior, o teste de regressão ${ }^{23}$ da Tabela 3 é comumente utilizado pela literatura econômica em testes de validação em uma regressão com vários países (Thirlwall, 2005).

Tabela 3. Teste de regressão da LTM para 2000-2013

\begin{tabular}{|c|c|}
\hline & Crescimento PIB per capita efetivo \\
\hline LTMS & $\begin{array}{c}1.172^{* * * *} \\
(.059)\end{array}$ \\
\hline Constante & $\begin{array}{c}-490.847 * * * \\
(173.639)\end{array}$ \\
\hline $\mathrm{F}(1,12)$ & 395.95 \\
\hline Prob $>$ F & .000 \\
\hline$n^{\circ}$ de observações & 14 \\
\hline
\end{tabular}

22 Pela Equação 17 que define a LTM, a taxa de crescimento da renda per capita de um país é diretamente proporcional à taxa de crescimento de suas exportações, com tal proporcionalidade existente inversamente (diretamente) relacionada à elasticidade setorial da demanda por importações (exportações). Essas elasticidades são ponderadas pelos coeficientes que medem a participação de cada setor no total das importações e exportações, respectivamente.

23 Dado o estimador utilizado, aplica-se a estratégia do teste de regressão em que a taxa de crescimento efetiva é regredida pela taxa de crescimento dada pelo modelo. 


\section{Restrições: inclinação: 1 ;} intercepto: 0

\section{.270}

R-squared

.9706

Adj R-squared

.9681

Notas: Os valores entre parênteses são os erros padrões robustos. ${ }^{* * *} \mathrm{p}<.01$, ${ }^{* *} \mathrm{p}<.05$, ${ }^{*} \mathrm{p}<.1$. Fonte: elaboração dos autores a partir dos dados do COMTRADE, BM e FMI.

Na Tabela 3, o teste F de restrições conjuntas não rejeita a hipótese nula de que a declividade da reta de regressão é igual a 1 e o seu intercepto, 0 . Isso implica que a LTM se configura como um estimador não viesado da taxa de crescimento efetiva. Cita-se, ainda, o elevado poder explicativo dado pelo $R$-squared.

Em outras palavras, ambos os testes implicam que o crescimento dos atuais países de renda média é compatível com as taxas restritas pelo equilíbrio do Balanço de Pagamentos. O erro de previsão do modelo, que superestima a taxa efetiva em $0.07 \%$, mostrou-se um bom estimador da taxa de crescimento efetiva no período do boom das commodities.

III.2. Composição estrutural do comércio internacional e as elasticidades-renda para a amostra de 15 países (2000-2013)

A validade e as conclusões em torno da LMT, referentes à amostra de 69 países apresentadas na seção anterior, corresponde a um exercício semelhante ao de Gouvêa e Lima (2013) e, que segundo estes mesmos autores, permite levantar conclusões do comportamento comum da amostra, bem como inspirar políticas voltadas para o crescimento. Todavia, como destaca Romero e McCombie (2015), pode haver falhas neste tipo de abordagem por pressupor que as elasticidades são iguais entre os países. Esta diferença nas elasticidades pode estar associada à heterogeneidade da amostra que também já foi abordada no trabalho.

Por isto, foram extraídos os 15 países com maior participação nas exportações e importações no final da amostra ${ }^{24}$, a fim de investigar o quanto as elastici-

24 Trabalhar e apresentar individualmente a análise dos 69 países seria inviável, inclusive, em termos de espaço. Para compor a amostra de 15 países bastou que a participação da soma das exportações com as importações do país fosse superior a 1.6\% da soma da amostra de 69 países. 
dades-renda individuais divergem daquelas apresentadas na seção anterior, além de explorar a heterogeneidade da amostra.

Tendo isto em vista, do ponto de vista das exportações, na Tabela 6 pode-se observar a elevação da média da participação nos setores, entre o início e final do período analisado, dos produtos primários, $12.47 \%$, dos recursos baseados em manufatura, $15.22 \%$, e de média intensidade tecnológica, 22.03\%. Esta elevação se deu em detrimento da redução da participação dos setores de baixa e alta intensidade tecnológica: $31.90 \%$ e $21.91 \%$, respectivamente.

Em termos percentuais, os maiores acréscimos na participação do setor primário ocorrem no Brasil e na Ucrânia, com elevação superior a 60\%, mas é no Cazaquistão e na Indonésia onde este setor de intensidade tecnológica é mais expressivo. Dos quatro países com redução na participação do setor primário, o maior percentual, próximo a 60\%, se dá no Vietnã. Nos recursos baseados em manufatura, a elevação da participação é mais expressiva nas Filipinas. Por outro lado, a redução no Egito apresenta maior decréscimo entre as quatro reduções observadas. Dos diferentes setores de intensidade tecnológica, a mitigação nas exportações foi mais expressiva no setor de baixa intensidade tecnológica, e todos os países, com exceção do Egito e do Vietnã, tiveram suas participações reduzidas. Estes decréscimos foram mais expressivos na Romênia e na Turquia. O setor de média intensidade tecnológica, relativamente elevado na pauta exportadora do México, da Hungria e da Romênia, teve sua participação média ampliada apesar dos decréscimos observados no Brasil, na África do Sul, na Ucrânia e, principalmente, no Cazaquistão. Já o setor de alta intensidade tecnológica, expressivo na composição das exportações das Filipinas e da Malásia, é o que apresentou maior dispersão na variação percentual entre as observações. Em termos de diferença entre 2013 e 2000, o decréscimo da participação da Tailândia e da Malásia foi maior.

A mesma análise é feita na Tabela 5 para as importações setoriais. Em suma, a média da importação entre os países só reduziu nos setores de baixa e alta intensidade tecnológica. É nos setores de média e alta intensidade tecnológica que se concentra, em média, o maior volume importado: em 2000 o valor agregado nestes dois setores foi de $55.56 \%$, enquanto em 2013 foi de $52.80 \%$. No setor de média intensidade tecnológica, em termos percentuais, destaca-se a elevação na importação da Ucrânia e a redução no Cazaquistão e na Indonésia. No setor de alta intensidade tecnológica, Vietnã e Indonésia ampliaram, percentualmente, o volume importado e, também percentualmente, a redução maior foi vista na Tailândia. Nos demais setores, cujo conteúdo tecnológico é menor, eles responderam por 
$44.44 \%$ e $47.20 \%$ do total importado em 2000 e 2013. Nenhum comportamento em comum foi observado entre os países, e cabe ressaltar, entretanto, sempre em termos percentuais, a ampliação na importação: i) no setor de baixa intensidade tecnológica na Malásia e no Vietnã; ii) no setor baseado em recursos nas Filipinas e na Turquia e; iii) no setor de baixa intensidade tecnológica na Ucrânia, no Brasil e no Cazaquistão. Ainda nos setores de menor intensidade tecnológica, quanto à redução nas importações, Turquia e Ucrânia se destacam no setor de baixa intensidade tecnológica; e Hungria e Argentina no setor de baixa intensidade tecnológica.

Tabela 4. Participações setoriais das exportações no início e no final do período de análise

\begin{tabular}{|c|c|c|c|c|c|c|c|c|c|c|}
\hline & \multicolumn{2}{|c|}{ PP } & \multicolumn{2}{|c|}{$\mathrm{RB}$} & \multicolumn{2}{|c|}{$\mathrm{LT}$} & \multicolumn{2}{|c|}{$\mathrm{MT}$} & \multicolumn{2}{|c|}{ HT } \\
\hline & 2000 & 2013 & 2000 & 2013 & 2000 & 2013 & 2000 & 2013 & 2000 & 2013 \\
\hline AFS & .189 & .270 & .349 & .335 & .114 & .069 & .298 & .290 & .050 & .036 \\
\hline ARG & .483 & .481 & .224 & .216 & .085 & .038 & .175 & .235 & .034 & .030 \\
\hline BRA & .212 & .345 & .277 & .339 & .124 & .051 & .258 & .220 & .128 & .044 \\
\hline CAZ & .746 & .809 & .095 & .102 & .076 & .015 & .073 & .038 & .011 & .037 \\
\hline EGI & .227 & .331 & .411 & .244 & .200 & .201 & .147 & .205 & .015 & .018 \\
\hline FIL & .035 & .091 & .063 & .208 & .115 & .076 & .113 & .185 & .674 & .440 \\
\hline HUN & .069 & .073 & .098 & .143 & .148 & .101 & .396 & .416 & .288 & .267 \\
\hline IND & .311 & .405 & .228 & .280 & .219 & .126 & .123 & .137 & .120 & .051 \\
\hline MAS & .106 & .194 & .117 & .237 & .086 & .091 & .159 & .163 & .531 & .315 \\
\hline MEX & .132 & .169 & .053 & .082 & .153 & .095 & .379 & .428 & .283 & .226 \\
\hline ROM & .069 & .103 & .206 & .179 & .446 & .200 & .204 & .423 & .075 & .094 \\
\hline TAI & .124 & .106 & .160 & .240 & .187 & .118 & .213 & .349 & .316 & 187 \\
\hline TUR & .104 & .091 & .122 & .175 & .477 & .356 & .218 & .335 & .079 & .043 \\
\hline UCR & .121 & .196 & .253 & .275 & .225 & .154 & .356 & .328 & .046 & .046 \\
\hline VIE & .517 & .212 & .067 & .082 & .312 & .328 & .046 & .099 & .058 & .279 \\
\hline Méd & .230 & .258 & .182 & .209 & .198 & .135 & .210 & .257 & .180 & .141 \\
\hline
\end{tabular}

Fonte: elaboração dos autores a partir dos dados do COMTRADE, BM e FMI. 
CRESCIMENTO SOB RESTRIÇÃO EXTERNA EM PAÍSES DE RENDA MÉDIA: UMA ANÁLISE EMPÍRICA...

Tabela 5. Participações setoriais das importações no início e no final do período de análise

\begin{tabular}{|c|c|c|c|c|c|c|c|c|c|c|}
\hline & \multicolumn{2}{|c|}{$\mathrm{PP}$} & \multicolumn{2}{|c|}{$\mathrm{RB}$} & \multicolumn{2}{|c|}{$\mathrm{LT}$} & \multicolumn{2}{|c|}{ MT } & \multicolumn{2}{|c|}{$\mathrm{HT}$} \\
\hline & 2000 & 2013 & 2000 & 2013 & 2000 & 2013 & 2000 & 2013 & 2000 & 2013 \\
\hline AFS & .200 & .212 & .146 & .187 & .104 & .112 & .319 & .316 & .232 & .172 \\
\hline ARG & .062 & .096 & .168 & .174 & .139 & .097 & .397 & .457 & .235 & .176 \\
\hline BRA & .163 & .168 & .189 & .181 & .064 & .090 & .339 & .377 & .245 & .184 \\
\hline CAZ & .093 & .121 & .227 & .171 & .107 & .156 & .451 & .403 & .123 & .150 \\
\hline EGI & .254 & .224 & .242 & .262 & .091 & .107 & .318 & .307 & .095 & .100 \\
\hline FIL & .165 & .216 & .095 & .183 & .074 & .068 & .209 & .219 & .456 & .313 \\
\hline HUN & .084 & .151 & .094 & .124 & .170 & .125 & .371 & .355 & .282 & .244 \\
\hline IND & .205 & .189 & .280 & .267 & .090 & .099 & .364 & .328 & .060 & .116 \\
\hline MAS & .083 & .164 & .099 & .209 & .074 & .076 & .245 & .240 & .499 & .311 \\
\hline MEX & .069 & .087 & .106 & .168 & .184 & .128 & .387 & .366 & .253 & .251 \\
\hline ROM & .159 & .145 & .136 & .140 & .227 & .193 & .315 & .351 & .163 & .171 \\
\hline TAI & .177 & .279 & .116 & .098 & .112 & .119 & .291 & .306 & .303 & .197 \\
\hline TUR & .189 & .112 & .140 & .215 & .108 & .130 & .378 & .408 & .184 & .134 \\
\hline UCR & .416 & .276 & .220 & .203 & .078 & .118 & .201 & .292 & .086 & .111 \\
\hline VIE & .067 & .120 & .227 & .159 & .174 & .157 & .387 & .305 & .146 & .259 \\
\hline Méd & .159 & .171 & .166 & .183 & .120 & .118 & .331 & .335 & .224 & .193 \\
\hline
\end{tabular}

Fonte: elaboração dos autores a partir dos dados do COMTRADE, BM e FMI.

Ainda visando explorar a heterogeneidade da amostra, as Tabelas 6 e 7 apresentam as estimações das elasticidades-renda para os mesmos quinze países de forma desagregada. Porém, a existência de resultados não estatisticamente significativos 
em determinados países e setores impossibilitou a estimação da LTM. A leitura dos resultados se restringe aos casos em que se obteve significância estatística ${ }^{25}$.

Destacam-se duas conclusões: i) o fato das elasticidades-renda das exportações terem sido, em média, maiores que as das importações; e ii) que inexistem semelhanças entre os resultados de cada país entre os setores de intensidade tecnológica.

Tabela 6. Elasticidade-renda desagregada das Exportações

\begin{tabular}{|c|c|c|c|c|c|}
\hline País & $\mathrm{PP}$ & $\mathrm{RB}$ & LT & MT & HT \\
\hline AFS & 1.205 & .084 & .925 & .543 & $4.311^{* * *}$ \\
\hline ARG & 2.173 & $1.788^{* *}$ & $3.264 * * *$ & $3.843^{* * *}$ & 2.044 \\
\hline BRA & $6.619 * * *$ & $3.631 * * *$ & $1.149 * * *$ & $2.786 * * *$ & .029 \\
\hline CAZ & 4.234 & -.871 & 5.012 & 2.841 & 6.699 \\
\hline EGI & 2.173 & $1.788 * *$ & $3.264 * * *$ & $3.843^{* * *}$ & 2.044 \\
\hline FIL & $5.073^{* *}$ & $5.862 * * *$ & $4.847 * * *$ & $6.463 * * *$ & 1.651 \\
\hline HUN & 2.647 & $3.324 * * *$ & 1.564 & $2.551^{*}$ & 1.496 \\
\hline IND & 1.693 & .925 & .393 & .218 & 4.009 \\
\hline MAS & .976 & .286 & 1.123 & $2.144^{* * *}$ & -1.072 \\
\hline MEX & 1.175 & $1.349 * *$ & $3.032 * * *$ & $2.458 * * *$ & $1.052 *$ \\
\hline ROM & $3.704 * * *$ & $2.066 * * *$ & $1.226 * * *$ & $2.532 * * *$ & $2.015^{*}$ \\
\hline TAI & $7.039 * * *$ & $3.932 * * *$ & -.648 & 1.926 & .741 \\
\hline TUR & .843 & $2.449 * *$ & $1.643^{* *}$ & $3.805 * * *$ & $2.486^{*}$ \\
\hline UCR & $6.129 * * *$ & $2.608 * * *$ & .990 & $3.737 * * *$ & $1.641^{*}$ \\
\hline VIE & $2.715^{*}$ & $2.533 * * *$ & .860 & .976 & 1.576 \\
\hline
\end{tabular}

Notas: $* * * \mathrm{p}<.01, * * \mathrm{p}<.05,{ }^{*} \mathrm{p}<.1$.

Fonte: elaboração dos autores a partir dos dados do COMTRADE, BM e FMI.

25 Para os valores estatisticamente significativos, os testes de Arellano e Bond apontam para a rejeição da hipótese nula de ausência de autocorrelação de primeira ordem e aceitação da existência de autocorrelação de segunda ordem dos resíduos; e os valores-p do teste de Hansen permitem aceitar as hipóteses de que os instrumentos utilizados na estimação dos modelos são válidos. 
CRESCIMENTO SOB RESTRIÇÃO EXTERNA EM PAÍSES DE RENDA MÉDIA: UMA ANÁLISE EMPÍRICA...

Tabela 7. Elasticidade-renda desagregada das importações

\begin{tabular}{cccccc}
\hline País & PP & RB & LT & MT & HT \\
\hline AFS & $1.630^{* * *}$ & $2.473^{* * *}$ & $1.880^{* * *}$ & $1.379^{* *}$ & .695 \\
\hline ARG & $2.866^{* * *}$ & $1.858^{* * *}$ & $4.582^{* * *}$ & $3.593^{* * *}$ & $5.583^{* * *}$ \\
\hline BRA & .099 & $1.209^{* *}$ & $2.138^{* * *}$ & $1.300^{* *}$ & $1.613^{*}$ \\
CAZ & .588 & -.489 & $1.021^{* * *}$ & .179 & $1.364^{* * *}$ \\
EGI & $1.563^{* * *}$ & $2.731^{* * *}$ & $2.787^{* * *}$ & $3.495^{* * *}$ & $2.797^{* * *}$ \\
\hline FIL & .267 & .152 & $.577^{* *}$ & $.700^{* *}$ & $1.353^{* *}$ \\
HUN & .790 & .138 & -.022 & .324 & -1.157 \\
\hline IND & $.741^{* *}$ & -.254 & $1.508^{* * *}$ & $2.159^{* * *}$ & .818 \\
\hline MAS & $1.145^{* *}$ & $.602^{* *}$ & .678 & $1.607^{* * *}$ & -.101 \\
\hline MEX & $3.158^{* * *}$ & $1.223^{* * *}$ & $2.070^{* * *}$ & $3.043^{* * *}$ & $1.935^{* *}$ \\
\hline ROM & $.980^{* *}$ & .207 & $1.133^{* * *}$ & $1.671^{* * *}$ & $1.096^{* *}$ \\
\hline TAI & -.312 & .317 & $1.308^{* *}$ & $1.122^{* *}$ & $1.517^{* *}$ \\
\hline TUR & $2.532^{* * *}$ & $2.105^{* * *}$ & $2.175^{* * *}$ & $1.906^{* * *}$ & $1.903^{* * *}$ \\
\hline UCR & $1.164^{* * *}$ & 1.247 & .941 & $2.168^{* * *}$ & $1.856^{* * *}$ \\
\hline VIE & $2.101^{* * *}$ & -.230 & $.711^{* *}$ & .165 & $1.871^{* *}$ \\
\hline
\end{tabular}

Notas: $* * * \mathrm{p}<.01, * * \mathrm{p}<.05, * \mathrm{p}<.1$.

Fonte: elaboração dos autores a partir dos dados do COMTRADE, BM e FMI.

Quando os resultados da Tabela 6 são comparados com os da Tabela 2, as elasticidades-renda das exportações da primeira não apenas se mostraram mais sensíveis nos setores de produtos primários e recursos baseados em manufatura, como foram menores no setor de alta tecnologia. Na análise desagregada, para todos os casos com significância estatística, as elasticidades foram maiores que a unidade. A demanda por produtos primários do Brasil, Filipinas, Ucrânia e Tailândia apresentaram elevada sensibilidade às variações da renda per capita mundial. Relativamente, as Filipinas apresentaram as maiores elasticidades-renda das exportações nos demais setores, com exceção do de alta tecnologia que não apresentou significância estatística.

Como discutido na Tabela 4, os países de renda média apresentam expressiva participação dos produtos primários e recursos baseados em manufatura nas suas composições setoriais das exportações. Associado às conclusões da Tabela 
6 é possível afirmar, pelo menos nesta amostra de quinze países, que o período analisado foi benéfico a eles, devido à variação da renda do per capita do resto do mundo num contexto de preços relativamente elevados das commodities e elasticidades-renda das exportações elásticas.

A da Tabela 6 contraria parte do referencial bibliográfico abordado neste artigo, que identifica nos setores de maior intensidade tecnológica as maiores elasticidades-renda ${ }^{26}$. Por outro lado, os valores observados para as elasticidades-renda das exportações corroboram a hipótese de Romero e McCobie (2015) sobre os equívocos em pressupor elasticidades-renda iguais para unidades de observação diferentes.

Do ponto de vista das elasticidades-renda das importações, Tabela 7, os valores assemelham-se com os observados na Tabela 2, salvo que na amostra de quinze países, em média, as elasticidades foram mais sensíveis. Na maior parte dos casos com significância estatística, as elasticidades foram elásticas, sendo que, relativamente, a Argentina apresentou os maiores valores.

A tabela 7 também está mais de acordo com a literatura econômica abordada, em que as elasticidades são maiores nos setores de maior intensidade tecnológica. Cruzando com os resultados da Tabela 5, entre os produtos de maior intensidade tecnológica, a participação da pauta importadora somente se elevou, entre 2000 e 2013, no setor de média intensidade tecnológica. Isto significa uma pressão menor sobre o balanço de pagamentos.

\section{CONCLUSÃO}

Este artigo buscou identificar na literatura pós-Keynesiana a existência de restrição ao crescimento do grupo dos atuais países de renda média imposta pelo balanço de pagamentos com base na Lei de Thirlwall Multisetorial de Araújo e Lima (2007). Esta análise se deu à luz de um período particularmente favorável a estes países, 2000 a 2013, que capta o boom nos preços internacionais das commodities, tendo em vista sua relevante participação no total exportado da amostra de países selecionada.

26 Não compõe, entre os objetivos deste trabalho, investigar as causas desta divergência dos resultados encontrados com a literatura econômica. Entretanto, cabe levantar a hipótese de que a seleção do período analisado, que capta a elevação dos preços internacionais de commodities, possa configurar enquanto uma das causas. 
Os resultados das estimativas para o agregado de 69 países, cujos sinais estão de acordo com a literatura abordada, indicaram que os setores de maior intensidade tecnológica foram os que apresentaram maiores elasticidades-renda das exportações e importações. As elasticidades-preço das importações sugerem que o valor importado, para os cinco setores analisados, é passível de alteração diante de políticas cambiais. Portanto, mudanças estruturais no sentido de ampliar a participação das exportações nos setores de maior intensidade tecnológica e redução das importações destes mesmos setores tendem a ser positivas do ponto de vista do crescimento econômico. As estimativas permitiram, ainda, constatar a persistência no tempo das exportações e importações.

O modelo utilizado se mostrou um bom estimador do crescimento real da economia do agregado de 69 países. e este crescimento, dados os testes de regressão, foi compatível com a taxa de crescimento sob restrição externa. Isso permite afirmar a validade da LTM e a relevância da restrição externa em explicar o crescimento econômico nos atuais países de renda média. Embora, como já mencionado, o valor exportado, via elevação dos preços das commodities, tenha sido favorável aos países de renda média, isto não foi suficiente ao elucidar a restrição externa a este grupo de países. Em termos, isto pode ser compreendido pela composição da pauta exportadora e importadora deste grupo de países: a exportação de produtos de baixa elasticidade-renda das exportações e importação de produtos de maior valor agregado e com elevada elasticidade-renda das importações. Ressalta-se que, pela análise Multisetorial, diferentes composições setoriais resultam em diferentes taxas de crescimento.

Por outro lado, não foi possível estimar a LTM para a amostra de quinze países devido a algumas das elasticidades da demanda não terem apresentado significância estatística. Em suma, as elasticidades-renda foram maiores na análise desagregada, o que destoou, no caso das elasticidades-renda das exportações, da literatura abordada, por atribuir aos setores de menor intensidade tecnológica maiores valores.

Do ponto de vista da composição setorial do balanço comercial, as exportações aumentaram e concentram-se nos setores de produtos primários e recursos baseados em manufatura. Já as importações concentram-se nos setores de maior intensidade tecnológica.

Salvo poucas exceções, a análise desagregada permitiu evidenciar que os países de renda média usufruíram de um contexto favorável em termos de crescimento: elevada elasticidade nos setores que concentram as exportações, preços das commodities elevados e elevação das importações nos setores com menor elasticidade-renda, salvo o acréscimo das importações no setor de média intensidade tecnológica. 


\section{REFERÊNCIAS}

Araujo, R. A. \& Lima, G. T. (2007). A structural economic dynamics approach to balance-of-payments constrained growth. Cambridge Journal of Economics, 31 (5), 755-774.

Araujo, R. A. \& Soares, C. (2011). 'Export Led Growth' x 'Growth Led Exports': What Matters for the Brazilian Growth Experience after Trade Liberalization? Munich Personal RePEc Archive. Working Paper Nº 30572.

Baltagi, B. H. (2005). Econometric Analysis of Panel Data. England: John Wiley \& Sons Ltd.

Bassos, M. C. (2014). A Economia Brasileira sob Restrição do Balanço de Pagamentos: Uma Análise Empírica da Lei de Thirlwall no Boom das Commodities. Trabajo publicado em Anais do $42^{\circ}$ Encontro Nacional de Economia. Disponível em https://en.anpec.org.br/previous-editions.php?r=encontro-2014.

Baum, C. F. (2006). An Introduction to Modern Econometrics Using Stata. College Station, TX: Stata Press.

Brandão, A. S. P. (2011). Preços elevados de commodities. Revista de Política Agrícola, 20 (1), 17-118.

Brandão, A. S. P. \& Alves, E. (2007). Análise de preços agrícolas. Revista de Política Agrícola, 16 (4), 129-131.

Carbinato, D. D. A. (2010). Crescimento econômico e estrutura produtiva no Brasil: análise das relações entre padrão setorial e restrição externa. Trabajo publicado em Anais do III Encontro da Associação Keynesiana Brasileira.

Carvalho, V. R. \& Lima, G. T. (2009). A restrição externa e a perda de dinamismo da economia brasileira: investigando as relações entre estrutura produtiva e crescimento econômico. Economia e Sociedade, 18 (1), 31-60.

Cimol, M., Porcile, G. \& Rovira, S. (2010). Structural Change and the BOP Constraint: Why Did Latin America Fail to Converge? Cambridge Journal of Economics, 34 (2), 389-411.

COMTRADE (2015). United Nations Commodity Trade Statistics Database. COMTRADE. Statistics Division. Disponível em http://comtrade.un.org/db/.

Duarte, P. C., Lamounier, W. M. \& Takamatsu, R. T. (2007). Modelos econométricos para dados em painel: aspectos teóricos e exemplos de aplicação à pesquisa em contabilidade e finanças. Trabajo publicado em Anais do $7^{\circ}$ Congresso USP de controladoria e contabilidade

Gouvêa, R. R. (2010). Padrão de especialização produtiva e crescimento econômico sob restrição externa: uma análise empírica. Dissertação de Mestrado da Universidade de São Paulo. 
Gouvêa, R. R. \& Lima, G. T. (2010). Structural change, balance-of-payments constraint, and economic growth: evidence from the multisectoral Thirlwall's law, Journal of Post-Keynesian Economics, 33 (1), 169-204.

Gouvêa, R. R. \& Lima, G. T. (2013) Balance-of-payments-constrained growth in a multisectoral framework: a panel data investigation, Journal of Economic Studies, 40 (2), 240-254.

Gill, I. \& Kharas H. (2007). An East Asian Renaissance: Ideas for Economic Growth. Washington D.C.: World Bank.

Hussain, M. N. (1999). The balance-of-payments coinstraint and growth rate difference. African Development Review, 11 (1), 103-137.

Instituto de Pesquisa Econômica Aplicada - Ipeadata. Dados macroeconômicos e regionais. Disponível em http://www.ipeadata.com.br.

Lall, S. (2002). The Technological Structure and Performance of Developing Country Manufactured Exports 1985-1998. QEH Working Paper Series QEHWPS No. 44.

Locatelli, R. L. \& Silva, J. A. B. (1991). Câmbio real e competitividade das exportações brasileiras. Revista Brasileira de Economia. 45 (4), 543-564.

Kaldor, N. (1957). A Model of Economic Growth. The Economic Journal, 67 (268), 591-624.

Kaldor, N. (1968). Productivity and Growth in Manufacturing Industry: a reply. Economica, 35 (140), 385-391.

Maluf, R. S. \& Speranza, J. (2013). Volatilidade dos preços internacionais e inflação de alimentos no Brasil: fatores determinantes e repercussões na segurança alimentar e nutricional. Câmara Interministerial de Segurança Alimentar e Nutricional (CAISAN). Ministério do Desenvolvimento Social e Combate à Fome; Caderno SISAN.

McCombie, J. S. L. (1989). Thirlwall's Law and balance-of-payments-constrained growth: a comment on the debate. Applied Economics, 21 (5), 611-629.

McCombie, J. S. L. (2011). Criticisms and defences of the balance-of-payments constrained growth model: some old, some new. PSL Quarterly Review, 64 (259), 353-392.

Pasinetti, L. (1981). Structural Change and Economic Growth - a Theoretical Essay on the Dynamics of the Wealth of the Nations. Cambridge, Cambridge University Press.

Queiroz, P. W. V., Spolador, L. A., Higachi, H. Y., \& Castilho, M. L. (2011). A Lei de Thirlwall Multisetorial: um teste empírico para a economia brasileira entre 1962-2008 e uma análise da estrutura produtiva nos governos Lula. Trabajo presentado em Anais do $14^{\circ}$ Encontro de Economia da Região Sul - Anpec Sul.

Romero, J. P. \& McCombie, J. S. L. (2015). The Multi-Sectoral Thirlwall's Law: Evidence from 14 Developed European Countries using Product-level Data. International Review of Applied Economics, 30 (3), 301-325. 
Romero, J. P., Silveira, F. \& Jayme J. F. G. (2011) Brazil: structural change and balance-of-payments constrained growth, CEPAL Review, 105, 173-195.

Soares, C., \& Teixeira, J. R. (2012). O Modelo de balanço de pagamentos restrito e desindustrialização: teoria e evidência para o caso brasileiro. Tese de doutorado do Programa de Pós graduação em Economia do Departamento de Economia da Universidade de Brasília.

Setterfield, M. (2006). Thirlwall's Law and Palley's Pitfalls: A Reconsideration. In P. Arestis, J. McCombie \& R. Vickerman. (eds). Growth and Economic Development: Essays in Honour of A. P. Thirlwall (pp. 47-59). Cheltenham, UK: Edward Elgar.

Thirlwall, A. P. (1979). The balance of payments constraint as an explanation of international growth rates differences. PSL Quarterly Review, 32 (128), 45-53.

Thirlwall, A. P. (1987). Nicholas Kaldor. New York, New York University Press.

Thirlwall, A. P. (1997). Reflections on the Concept of Balance-of-Payments-Constrained Growth. Journal of Post Keynesian Economics, 19 (3), 377-385.

Thirlwall, A. P. (2005). A Natureza do crescimento econômico: Um referencial alternativo para compreender o desenho das nações. Brasília: Ipea.

Thirlwall, A. P. (2011). Balance of Payments Constrained Growth Models: History and Overview. PSL Quarterly Review, 64 (259), 307-351.

Tharnpanich, N. \& McCombie, J. S. L. (2013) Balance-of-payments constrained growth, structural change, and the Thai economy, Journal of Post Keynesian Economics, 35 (4), 569-97.

Verissimo, M. P. \& Xavier, C. L. (2013). Taxa de câmbio, exportações e crescimento: uma investigação sobre a hipótese de doença holandesa no Brasil. Revista de Economia Política, 33 (1), 82-101.

Wooldridge, J. M (2002). Econometric Analysis of Cross Section and Panel Data. Cambridge, Massachusetts: The MIT Press.

World Development Indicators do World Bank. Data. Disponível em https://data. worldbank.org/indicator/NY.GDP.MKTP.CD

(C) 2020 por los autores; licencia no exclusiva otorgada a la revista Estudios económicos. Este artículo es de acceso abierto y distribuido bajo los términos y condiciones de una licencia Atribución-No Comercial 4.0 Internacional (CC BY-NC 4.0) de Creative Commons. Para ver una copia de esta licencia, visite http://creativecommons.org/licenses/by-nc/4.0 